\title{
Elementary School Teachers' Epistemological Beliefs as Predictors of Their Inquiry-Based Practices in Science Instruction
}

\author{
David F. Samuel", Babalola J. Ogunkola \\ School of Education, University of the West Indies, Cave Hill Campus, Bridgetown, Barbados \\ Email address: \\ swanlake_sea@hotmail.com (D. F. Samuel), david.samuel@cavehill.uwi.edu (D. F. Samuel), drbeejay@hotmail.com (B. J. Ogunkola), \\ babalola.ogunkola@cavehill.uwi.edu (B. J. Ogunkola)
}

\section{To cite this article:}

David F. Samuel, Babalola J. Ogunkola. Elementary School Teachers' Epistemological Beliefs as Predictors of Their Inquiry-Based Practices in Science Instruction. International Journal of Elementary Education. Vol. 4, No. 6, 2015, pp. 101-112. doi: 10.11648/j.ijeedu.20150406.11

\begin{abstract}
Trained elementary school teachers' epistemological beliefs were measured using Schraw, Bendixen and Dunkle (2002) adaptation of Schommer's (1990) epistemological belief inventory. The population consisted of 424 trained teachers. The levels of IBI of a $25 \%$ random sample of these teachers were also determined using an observational rating scale. A determination was also made of any significant differences in teachers beliefs based on relevant grouping variables. Correlation analysis was used to determine the extent to which teachers' epistemological beliefs predicted their inquiry-based instructional practices in science. Teachers' epistemological, beliefs were found to be generally moderately favourable to their practice of IBI. Significant differences in teachers' epistemological beliefs $(\mathrm{df}=3, \mathrm{~F}=2.881 . \mathrm{p}<.05)$ were found with these beliefs increasing with teaching experience. Teachers' inquiry-based practices were found to be at the developing inquiry level. These findings are significant in that they show the importance of teachers' educational beliefs in influencing their IBI practices and highlight the importance of promoting an academic and societal culture that promotes the development of more sophisticated students' epistemologies.
\end{abstract}

Keywords: Inquiry-Based Instruction, Beliefs, Epistemological Beliefs

\section{Introduction}

This study concerns the implementation of the Organization of Eastern Caribbean States (OECS) Harmonized Primary School Science Curriculum in St. Lucia and focuses on the impact of teachers' beliefs on their inquiry-based instructional practices (IBI) in science. This curriculum clearly identifies the requirement for teaching and assessment strategies associated with inquiry-based instruction. For example, the following principles are listed as what should be used to guide instructional strategies.

1. Learning is an interactive activity.

2. Students should be made to see the relevance in the science concepts being learnt. So investigations should, as far as possible, be linked to relevant experiences of the students.

3. Student experiences of phenomena should as far as possible precede any abstract presentation of such phenomena.
4. Students require adequate time and resources to effectively learn scientific and technological concepts.

5. The teacher should become a facilitator of students' learning. His or her role must be the facilitation of students' learning rather than the presenter of content.

\subsection{Elementary School Science Teaching in St Lucia}

According to the 2011-2012 Education and Culture Statistical Digest, as of the 2011/2012 academic year 90\% of primary school teachers are qualified teachers (Data Management Corporate Planning Unit, M. O. E., 2011). These teachers have either a University of the West Indies (U. W. I) Certificate or Associate Degree in Primary Education where the science education programme specifically enables training in the theory and practice of inquiry-based instruction (IBI). It is therefore a valid assumption that these trained teachers have both the theoretical and practical knowledge of inquiry-based instruction. Despite these facts, there is a strong perception 
among science educators and curriculum officers that a majority of teachers in both primary and secondary schools in St. Lucia mainly use the traditional didactic approaches in their implementation of science curricula.

The important question which arises is what are the factors which would cause trained teachers to move away from the teaching approaches and strategies learnt and practiced at teachers' college and instead use strategies deemed inappropriate by the education literature? In seeking to answer this question it should be noted that primary school teachers in St. Lucia are generally not expected to account for the strategies they use to teach their lessons on a day to day basis. Although there may be some lesson observations by principals, district education officers and curriculum officers, these are normally very infrequent and so inadequate enough to actually affect the teaching strategies that a teacher decides to use on a day to day basis. There are likely to be other more influential factors that may have a stronger impact on the instructional decisions made by a teacher in the classroom.

\subsection{Teachers' Educational Beliefs and Their Instructional Practices}

It was from the 1970 s that questions were raised by researchers about the influence of teachers' knowledge structures on their instructional decisions (E. g. Alexander, 1992; Anderson et al, 1977; Perkins and Simmons, 1988). Part of this debate was identified by Boldrin and Mason (2009) as involving epistemic questions about the nature of knowing and believing in instructional practice.

Since the 1980s, there have been several studies investigating the role of individual's beliefs in their actions and decision making. Pajares (1992) did a synthesis of such studies and indicated that they were generally based on the assumption that beliefs are the best indicators of the decisions individuals make throughout their lives (e. g. Bandura, 1986; Dewey, 1933; Nisbett and Ross, 1980; Rokeach, 1968). It is therefore the researchers' contention, and a hypothesis for this study, that there are a variety of beliefs that can be held by teachers that can have a significant impact on their decisions to use particular instructional practices in science. The research literature identifies three possible belief constructs that are relevant within the St Lucian context: epistemological beliefs, beliefs about science teaching and learning, and science teaching efficacy beliefs. The researchers conceptualized a fourth belief construct which they termed applicability beliefs (Samuel and Ogunkola, 2013).

The first part of the research investigated teachers' applicability beliefs and beliefs about science teaching and learning and was published in 2013 in the journal "International Education Studies". It was found that teachers' IBI were at the unsatisfactory developing inquiry level, their applicability beliefs were barely moderately favourable to their IBI, while their beliefs about science teaching and learning were favourable. In addition, while teachers' science teaching and learning beliefs were found to be significant and moderately positive predictors of their IBI, their applicability beliefs appeared to function as a moderating variable that limited the effect of these favourable beliefs on IBI (Samuel and Ogunkola, 2013).

This study reports on the findings of the extent to which teachers' epistemological beliefs serves as predictors of their IBI. In defining epistemological beliefs as beliefs about knowing and learning, Jones and Carter (2007) indicated that these beliefs play a mediating role in how individuals process new information. With reference to teachers, Jones and Carter also suggested that personal epistemologies developed as a result of formal and informal learning experiences and are important in that they serve as "mental exemplars for constructing and evaluating their own teaching practice" (p. 1072).

St. Lucian society provides many avenues for informal as well as formal learning opportunities that may have as great an impact on individuals' thought processes as the classroom environment. Most importantly, it is a predominantly Christian society and hence the teachers in primary schools are predominantly Christian. Religious knowledge instruction has traditionally been, and still is, an important part of the school curriculum. In addition, the nature of St. Lucian society provides strong evidence of a heavy reliance on the ideas of authority sources. For example the tendency to only accept what is considered to be 'normal' ways of living and reject those that are considered 'different'. Also, the country's politics has generally been very tribal or clannish in nature with the blind acceptance by many persons of the policies of one of the two main political parties. With regards to the school curriculum, there has been a constant complaint from education authorities that it is largely being implemented in the traditional content-focused way with little opportunities for the exploration of individual ideas and the creativity of students. These and other societal factors may possibly be instrumental in the development of more simplistic epistemological beliefs among the St Lucian population. This research is, in part, an investigation of this among elementary school teachers.

\section{Theoretical Framework}

\subsection{Inquiry-Based Instructional Practices in Science}

The curriculum developers of the elementary school curriculum utilized the National Science Education Standards (NSES) produced by the National Research Council (NRC) in the USA to provide guidelines for the implementation of an inquiry-based instructional approach to science education at the elementary school level. The NSES were published in 1998 to "emphasize a new way of teaching and learning about science that reflects how science itself is done, emphasizes inquiry as a way of achieving knowledge and understanding about the natural world..."(NRC, 1996, p.9). These standards, together with the publication 'Benchmarks for Science Literacy' produced by project 2061 of AAAS, offered a comprehensive guide for inquiry-based science instruction (Bybee, Powell and Trowbridge, 2008).

The requirement for IBI practices in the teaching of science in elementary schools in St. Lucia is not only clearly 
articulated in the primary science curriculum but also the teacher education curriculum. Initial teacher training in St. Lucia is of two year duration and trainees may specialize in primary or secondary teacher education. Most trained teachers in St Lucia have either a University of the West Indies (U. W. I) Certificate or Associate Degree in Primary Education. In addition, a number of these teachers have received further training at the Bachelors of Education level and some at the Masters of Education. IBI approaches to instruction are emphasized in both the science and mathematics education curricula of the U. W. I. Certificate and Associate Degree programmes in primary education. A large number (90\%) of primary school teachers in St. Lucia are trained and are therefore assumed to have both the theoretical and practical knowledge of inquiry-based instruction.

Despite these facts, there is a strong perception among science educators and curriculum officers that a majority of teachers in both primary and secondary schools in St. Lucia mainly use the traditional didactic approaches in their implementation of science curricula. From this researcher's experience as a secondary school science teacher, primary school principal, and teacher education lecturer, these reports appear valid. Therefore, there seems to be an apparent disconnect between the strategies learnt and practiced by teachers at their institution of teacher education with those used by these same teachers at their schools of employment.

Primary school teachers in St. Lucia are generally not expected to account for the strategies they use to teach their lessons on a day to day basis. Although there may be some lesson observations by principals, district education officers and curriculum officers, these are normally very infrequent and so inadequate enough to actually affect the teaching strategies that a teacher decides to use on a day to day basis. There are likely to be other more influential factors that may have a stronger impact on the instructional decisions made by a teacher in the classroom.

\subsection{Beliefs}

Many researchers have explored and debated questions about the nature of knowledge and believing (E. g. Boldrin and Mason, 2009; Nespor, 1987; Nisbett and Ross, 1980; Pajeres, 1992). Nisbett and Ross (1980) had conceptualized knowledge as composed of a cognitive component as well as a belief component possessing elements of evaluation and judgment. Other researchers have sought a separate conceptualization of knowledge and beliefs. Nespor (1987) for example, differentiated the two constructs based on stronger evaluative and affective components of beliefs. Ernest (1989), on the other hand, identified knowledge as the cognitive outcome of thought and beliefs, the affective outcome (cited in Pajares, 1992). Boldrin and Mason (2009) supported these ideas by claiming that knowledge is conceived by individuals as certain and based on objective evidence while beliefs are considered as uncertain, unproven, 'personal truths', and not necessarily supported by objective evidence.

Irez (2007) synthesized the definitions of a number of researchers (e. g. Clark and Peterson, 1986; Nespor, 1987;
Pajares, 1992; Richardson, 1996) and provided a definition considered applicable to this research.

Beliefs are psychological constructs that (a) includes understandings, assumptions, images or propositions considered to be true, (b) drive a person's actions and support decisions and judgments, (c) have highly variable and uncertain linkages to personal, episodic and emotional experiences, (d) although undeniably related to knowledge, differs from knowledge in that beliefs do not require a condition of truth" (p. 17)

With regards to teachers, various researchers have described beliefs related to the teaching-learning process as evolving over time due to a variety of factors including cultural influences and teachers' experiences of schooling and instruction (e. g. Lortie, 1975; Richardson, 1996). Over the last thirty years, researchers have identified a variety of beliefs which may impact the instructional practices of teachers. For example, Pajares (1992) indicated that the construct of educational beliefs is broad and encompassing, and classified it into teacher efficacy beliefs, self-efficacy, self-esteem, and epistemological beliefs. The aim of this research was to investigate the level of St Lucian teachers' epistemological beliefs and the extent to which these beliefs serve as predictors of the level of inquiry-based practices in science instruction.

\subsubsection{Epistemological Beliefs}

Yilmaz-Tuzan and Topcu (2008) cites a definition of epistemology by Hofer (2002) as the "origin, nature, limits, methods and justification of human knowledge" (p.65). So epistemological beliefs can simply be defined as individual's beliefs about the nature of knowledge and how we come to know. Jones and Carter (2007) went further and described these beliefs as playing a mediating role in an individual's processing of new information. Yilmaz-Tuzan and Topcu (2008) described the possibility of an individual holding several epistemological beliefs at the same time, and that these beliefs shape a person's epistemology.

Epistemological beliefs are of particular relevance to education, particularly the teaching-learning process, since on one hand, individuals' personal epistemologies may most likely have been strongly influenced by their experiences as students in schools. On the other hand, teachers' personal epistemologies would most likely influence the way they conceptualize the teaching-learning process and hence, what learning is like for individual students. Jones and Carter (2007) also expressed the view that teachers' personal epistemologies may serve as mental exemplars for "constructing and evaluating their own teaching practices" (p.1072). It is therefore also likely that teachers' epistemologies may also be reflected in their classroom behavior.

Researchers have provided different interpretations as to what generally constitutes personal epistemologies, and how these epistemologies develop in individuals. According to Yilmaz-Tuzan and Topcu (2008), some researchers are of the view that personal epistemologies develop in stages similar to Piagetian cognitive development. Two key stages in that 
development were identified by Yilmaz-Tuzan and Topcu (2008) as:

1. Knowledge seen as certain and authoritative.

2. Knowledge seen as "cumulative constructions of observations but subject to judgment by different individuals" p. 66).

Yilmaz-Tuzan and Topcu (2008) identified other researchers as having described personal epistemologies as a collection of beliefs (e. g. Schommer, 1990). They adopted a multi-dimensional perspective which was explained by Yilmaz-Tuzan and Sami Topcu (2008) as individuals having a multiplicity of beliefs about the certainty of knowledge, source of knowledge, justification of knowledge, acquisition of knowledge and the structure of knowledge. Using this multi-dimensional perspective, Schommer hypothesized five epistemological beliefs:

3. Certain knowledge - beliefs about the stability of knowledge ranging from unchanging to tentative.

4. Simple knowledge - beliefs about the structure of knowledge ranging from isolated bits and pieces to integrated concepts.

5. Omniescent authority - beliefs about the source of knowledge ranging from omniescent authority to reason and empirical evidence.

6. Quick learning - beliefs about the speed of learning ranging from quick or not at all to gradual.

7. Innate ability - beliefs about ability to learn ranging from fixed at birth to improvable.

With regards to teachers, Mann (2014), although finding no significant differences between the epistemological beliefs of pre-service and in-service teachers, found significant differences among the dimensions of epistemological beliefs for both groups of teachers. It seems, therefore, that the various dimensions of epistemological beliefs develop differently in individuals based on their experiences. Chi-Kin Leo, Zhang, Song \& Huang (2013) suggested that these beliefs could actually be shaped by cultural influences, former parenting and schooling experiences. Ozdemir and Koksal (2014) also found that teachers have sophisticated epistemological beliefs in the dimension that learning depends on talent and effort but only partly sophisticated beliefs in the dimension that there is one unchanging truth.

\subsubsection{Teachers' Epistemological Beliefs and Their Instructional Practices}

Both views of the development of epistemological beliefs recognize that there is a gradual continuum of which knowledge could be perceived by individuals. This continuum ranges from a view of knowledge as certain and authoritative to knowledge that is tentative, uncertain, and based on human reasoning and empirical evidence. The relevance to science teaching and learning can be clearly seen. Teachers whose epistemological beliefs are more dualist in nature, and hence, sees knowledge as certain and authoritative, may be more inclined to use the traditional, teacher-centered approaches to instruction than studentcentered IBI. On the other hand, teachers with more relativist beliefs, who see knowledge as tentative and based on human reasoning and empirical evidence, may be more inclined to use IBI rather than the traditional approaches.

When the other dimensions of Schommer's hypothesized epistemological beliefs are examined, the same reasoning could be applied to show that the nature of a teacher's epistemological beliefs may be reflected in the teacher's approach to instruction. For example, for the dimension 'simple knowledge', if a teacher sees knowledge as isolated bits and pieces, then his or her teaching strategies may be inclined towards traditional content-focused, text-book driven strategies. In contrast, a teacher who sees knowledge as integrated may utilize more student-centered strategies aimed at implementing a more cohesive and relevant science curriculum. For the dimensions of 'quick learning' and 'innate ability', teachers who believe that students' ability to learn is fixed, may be inclined to use teacher-centered approaches, while those who believe that all students can learn, albeit at different rates, and students ability to learn can be improved, will be more inclined to use student-centered approaches.

The suggested relationships between teachers' epistemologies and their teaching practices have been studied by various researchers (e. g. Schommer, 1994; Song, Hannafin and Hill, 2007; Stoddert, 1994). Generally, these researchers found that teachers' epistemologies influence their daily practices and, hence, affect the planning of teaching, teacher-student interactions, and ultimately student learning. Recent studies have established this link between teachers' personal epistemologies and their instructional practices. Hurling (2014) studied the effect of teachers' epistemological beliefs on practice and found that these beliefs play a role in the way instruction is approached in either a constructivist or non-constructivist manner. A positive correlation was also found between personal epistemological beliefs and understanding of the nature of science which, in itself, predicted constructivist practices. In a similar study, Mann (2014) found significant and positive relationships between the overall epistemological beliefs and instructional practices of pre-service and in-service teachers.

\subsubsection{Socio-cultural Traditions and Epistemological Beliefs}

A number of researchers have found a variety of links between a country's socio-cultural context and the level of students' epistemological beliefs (e. g. Chan and Elliot, 2000; Chen and Elliott, 2004; Hofer, 2008; Rizk, Jaber, Halwany \& Boujoude; 2011, Chi-Kin Leo et al, 2013). Since baseline data on epistemological beliefs were originally compiled in the United States, more current studies have tended to compare populations in the US with other countries. For example, the research of Karabenick and Moosa (2005) found that the customs and traditions of Omani students influenced their beliefs that the source of scientific knowledge is science authority figures. They compared this with the more sophisticated beliefs of US students who expressed more distrust in scientific authorities as sources of scientific knowledge. Similarly, the research of Chen and Elliott (2004) showed that student teachers in Hong Kong 
showed the simplistic belief of trust in science related authorities. These beliefs were explained in terms of various particularities of Asian culture where the respect shown to authority figures is reflected in the general acceptance of their ideas. One authority source that is highly valued in Asian as well as Middle Eastern countries is religion. As indicated by Rizk et al (2011) widespread beliefs in holy texts such as the bible and the Quran projects a possible view that knowledge is stable and static. In comparison in the US, the separation of church and state is enshrined in the constitution and there has been a removal of religious influences in the curriculum of public schools.

Research hypothesis.

St. Lucian elementary school teachers have generally simplistic epistemological beliefs which are reflected in low levels of inquiry based instructional practices in science.

Research questions.

1. What is the level of primary school teachers' epistemological beliefs?

2. Are there significant differences in teachers' epistemological beliefs based on:

a) Years of experience

b) Qualifications in science.

c) Interactions between years of experience and science qualifications?

d) Highest educational attainment (Degree versus nondegree)

3. How do the levels of primary school teachers' epistemological beliefs predict their use of IBI practices?

\section{Research Methods}

The research design was descriptive and correlational where quantitative procedures were used in the collection and analysis of data. This involved:

a) Survey techniques used to measure teachers' epistemological beliefs.

b) T-test and ANOVA procedures used to determine if there were any significant differences in teachers' epistemological beliefs based on different groups in the population.

c) Correlation analyses used to determine the extent to which the epistemological beliefs of primary school teachers predict their use of inquiry-based instructional practices.

\subsection{Population}

St. Lucia has eight educational districts identified as district 1 to district 8 . Trained teachers from the junior primary grades (i. e. grades 3 to 6 ) from districts 1 to 8 were selected as the population for the study. Trained teachers were selected because of their assumed knowledge of inquiry-based techniques in science instruction. Data from the 2011 Education and Culture Statistics Digest of St. Lucia (Data Management, Corporate Planning Unit, M. O. E., 2011) indicated that there are 424 trained teachers in these districts teaching grades 3-6 which therefore represents the total population for the study.

\subsection{Selection of Samples}

A sample of schools from each district was selected for the initial pilot testing of the survey instrument. The schools were selected by a combination of random and purposive sampling. The schools that were purposively selected were chosen because these schools had a very small population of teachers and students and very small class sizes. Three of the schools actually practiced multi-grade teaching. Hence these schools had some marked differences from the rest of the schools in the population which warranted their exclusion from the study sample. The other schools were randomly selected from the eight districts. A total of 15 schools and 83 teachers were selected for the pilot testing.

The sample for the survey to determine and measure the epistemological beliefs of trained primary school teachers was obtained by subtracting the sample for the pilot testing from the total population. It was deemed necessary to use the whole sample because of its relatively small size and to enable a greater level of accuracy and robustness in the analysis of the data and interpretation of the results. The sample for the survey was therefore 341 .

Stratified random sampling techniques were used to select $25 \%$ of the population (approximately 87 teachers) for the lesson observation phase of the study.

\subsection{Data Collection Instruments}

\subsubsection{The Questionnaire}

The questionnaire was constructed to obtain data from the population required for measurement of their epistemological beliefs. In addition, items were included to obtain demographic information necessary for answering the research questions.

Section A was designed to obtain demographic information from the population. So this section provided information on the independent variables:

- Teaching experience

- Qualifications in science

- Highest educational qualification.

Section B was the Epistemological Belief Inventory. This inventory was developed and originally used by Schraw, Bendixen and Dunkle (2002) from their revision of a belief inventory designed by Schommer (1990). Schommer's inventory originally had 63 items and was based on five hypothesized epistemological belief constructs. These were identified by Yilmaz-Tuzan and Topcu (2008) as:

1. Certain knowledge - beliefs about the stability of knowledge ranging from the simple belief that knowledge is unchanging to the more sophisticated belief that knowledge is tentative.

2. Simple knowledge - beliefs about the structure of knowledge ranging from the more simple belief that knowledge consists of isolated bits and pieces of information to the more sophisticated belief that 
knowledge consists of integrated concepts.

3. Omniscient authority - beliefs about the source of knowledge ranging from the simple belief that knowledge originates from omniscient authority to the more sophisticated belief that knowledge is based on reason and empirical evidence.

4. Quick learning - beliefs about the speed of learning ranging from the simple belief that learning occurs quickly or not at all to the more sophisticated belief that learning occurs gradually.

5. Innate ability - beliefs about ability to learn ranging from the more simple belief that the ability to learn is fixed from birth to the more sophisticated belief that learning ability is improvable.

6. The epistemological belief inventory for this questionnaire contains the 28 items of the instrument designed by Schraw, Bendixen and Dunkle (2002). The items are arranged in a 5-point Likert scale and numbered from B1 to B28. Based on Schommer's five underlying dimensions the instrument was constructed as shown in table 1 .

Table 1. Organization of epistemological belief inventory questions according to underlying factors.

\begin{tabular}{llll}
\hline Factor & No. of items & Items & Example of item \\
\hline Simple knowledge & 7 & $1,10,11,12,17,21,22$ & 11. The best ideas are often the most simple. \\
Certain knowledge & 5 & $2,6,18,23,28$ & 2. What is true is a matter of opinion. \\
Omniescent authority & 5 & $4,7,19,25,26$ & 26. People should not question authority. \\
Innate ability & 6 & $5,8,13,14,16,24$ & 24. Smart people are born that way. \\
Quick learning & 5 & $3,9,15,20,27$ & 3. Students who learn things quickly are most successful. \\
\hline
\end{tabular}

\subsubsection{Lesson Observation Rating Scale}

The instrument for the lesson observations was adapted from a model of inquiry-based instructional assessment designed by Marshall, Smart and Horton (2010). The instrument is referred to as the Electronic Quality of Inquiry Protocol (EQUIP) and was constructed and designed to allow a comprehensive and quantitative measurement of various aspects of inquiry-based instructional activities used by teachers during instruction. Marshall, Smart and Horton (2010) outlined steps taken to thoroughly check the instrument for face validity, internal consistency, inter-rater reliability and content and construct validity.

The rating scale was designed to assess four constructs implicit to IBI practices. These are:

1. Instructional factors: How effectively the teacher used the recommended inquiry-based instructional strategies.

2. Discourse factors: Effective use of inquiry-based verbal interactions like questioning and discussion.

3. Assessment factors: Effective use of formative and summative assessment techniques.

4. Curriculum factors: Effective engagement with the content e. g. adequate depth and integration with investigations.

Each construct was further divided into appropriate subconstructs and the assessor determines the level of inquiry observed based on the rating scale in the table. Marks are awarded for each sub-construct as follows:

1. Pre-inquiry.

2. Developing inquiry.

3. Proficient inquiry.

4. Exemplary inquiry.

\subsection{Data Analysis Procedures}

\subsubsection{Scoring for the Questionnaire Responses}

Responses for each item of the Likert scales were coded so that a score of 5 represented the most sophisticated belief that was most favourable to IBI practices and a score of 1 , the belief that was most simplistic and unfavourable to IBI practices. The score obtained by each participant for each item of the questionnaire was entered into SPSS 18. Demographic information from section $A$ of the questionnaire, which was necessary to answer the research questions, was also entered into SPSS as grouping variables.

\subsubsection{Analytical Procedures for Research Question 1}

The mean scores for all the participants for the epistemological belief inventory were obtained and interpreted as shown in table 2 .

Table 2. Interpretation of mean score for epistemological belief construct.

\begin{tabular}{ll}
\hline Range of mean belief score & Level of belief \\
\hline$<2.04$ & Very unfavourable for IBI \\
$2.05-3.04$ & Unfavourable for IBI \\
$3.05-4.04$ & Moderately favourable for IBI \\
$4.05-4.50$ & Favourable for IBI \\
$4.51-5.00$ & Very favourable for IBI \\
\hline
\end{tabular}

For a more in-depth analysis, the mean scores of all the participants for each of the underlying factors of the belief constructs were also obtained and interpreted as in table 2 . In addition, frequency and cumulative frequency tables were also drawn.

\subsubsection{Analytical Procedures for Research Question 2}

Two-way ANOVA procedures were conducted to determine how the measured level of teachers' beliefs varied depending on teacher experience and qualifications. The ttest was used to detect any significant differences in teachers' beliefs depending on teachers' educational attainment.

\subsubsection{Analytical Procedures for Research Question 3}

Multiple regression analyses were used to determine how teachers' epistemological beliefs predict their level of IBI.

Out of the sample of 341 teachers for the survey administration, 302 questionnaires were collected and analyzed, a response rate of $88.6 \%$. The reliability of the questionnaire was found to be $64.5 \%$. 


\section{Data Analysis}

\subsection{Analysis of Research Question 1}

What is the level of primary school teachers' epistemological beliefs?

A mean of 3.4 out of 5 was found which was interpreted by the researchers as moderately favourable towards the practice of IBI.

Table 3 below shows the frequency distribution of teachers' epistemological belief scores.

Table 3. Frequency distribution of epistemological belief scores.

\begin{tabular}{lllll}
\hline $\begin{array}{l}\text { Epistemological } \\
\text { belief mean score }\end{array}$ & Frequency & $\%$ & $\begin{array}{l}\text { Cumulative } \\
\text { percentage }\end{array}$ & Interpretation \\
\hline $1.00-2.04$ & 0 & 0 & 0 & $\begin{array}{l}\text { Very } \\
\text { unfavourable }\end{array}$ \\
$2.05-3.04$ & 44 & 14.6 & 14.6 & $\begin{array}{l}\text { Unfavourable } \\
\text { Moderately } \\
\text { favourable }\end{array}$ \\
$4.05-4.04$ & 252 & 83.4 & 98.0 & $\begin{array}{l}\text { Favourable } \\
\text { Very } \\
\text { favourable }\end{array}$ \\
\hline
\end{tabular}

These results show that only $2 \%$ of the teachers have epistemological beliefs favourable to the practice of IBI. The large majority (83.4\%) have moderately favourable beliefs while $14.6 \%$ have epistemological beliefs that are unfavourable to the practice of IBI.

The mean for each underlying construct for the epistemological beliefs are shown in table 4 below. These, as well as the underlying constructs for the other beliefs, are abbreviated for further use.

Table 4. Means for underlying constructs of epistemological beliefs.

\begin{tabular}{llll}
\hline Sub-Construct & Mean score /5 & Interpretation \\
\hline Simple knowledge & 3.2 & Moderately favourable \\
Certain knowledge & 3.2 & Moderately favourable \\
Omniscient authority & 3.1 & Moderately favourable \\
Innate ability & 3.2 & Moderately favourable \\
Quick learning & 4.1 & Favourable \\
\hline
\end{tabular}

The findings indicate that only with the quick learning subconstruct did the sample record a belief score favourable to IBI. This indicates that teachers generally tend to believe that all their students are generally capable of learning but at different rates. For the other sub-constructs, the teachers' beliefs scores were only moderately favourable, with omniscient authority recording the lowest score of 3.1 indicating a barely moderately favourable belief supporting IBI.

\subsection{Analysis of Research Question 2}

Are there significant differences in teachers' beliefs based on:

a) Years of experience.

b) Qualifications in science.

c) Interactions between years of experience and science qualifications? d) Highest educational attainment (Degree versus nondegree).

Table 5 shows the results of the three-way ANOVA with teachers' epistemological belief mean score as the dependent variable and years of experience and science qualifications as the independent variables.

Table 5. Two-way ANOVA for epistemological beliefs.

\begin{tabular}{llll}
\hline Independent variable & Df & F & Sig \\
\hline T. exp & 3 & 2.881 & $.036^{*}$ \\
Sci. qual. & 2 & .882 & .415 \\
T Exp+Sci qual & 6 & 1.686 & .124 \\
\hline
\end{tabular}

+ Interactions. *significant $(\mathrm{p}<.05)$.

The findings significant differences in teachers' epistemological beliefs based on teaching experience $(\mathrm{df}=3$, $\mathrm{F}=2.881, \quad \mathrm{p}<.05)$. Although no significant pairwise differences were revealed by the post hoc comparisons, it was clear that teachers' epistemological beliefs increased with teaching experience.

When the two-way ANOVA was conducted to detect any group differences for the underlying constructs of teachers' epistemological beliefs, significant differences were only found for the simple knowledge beliefs of teachers (table 6) based on their science qualifications $(\mathrm{df}=2, \mathrm{~F}=5.936$, $\mathrm{p}=.003)$, and teaching experience $(\mathrm{df}=3, \mathrm{~F}=3.814, \mathrm{p}=.010)$.

Table 6. Two-way ANOVA for simple knowledge beliefs.

\begin{tabular}{llll}
\hline Independent variable & Df & F & Sig \\
\hline T. exp & 3 & 3.814 & $.010^{*}$ \\
Sci. qual. & 2 & 5.936 & $.003^{* *}$ \\
T Exp+Sci qual & 6 & 2.334 & $.032^{*}$ \\
\hline
\end{tabular}

+ Interactions. *significant $(\mathrm{p}<.05) * *$ significant $(\mathrm{p}<.005)$.

Post-hoc Hochberg Pairwise comparisons revealed that the simple knowledge beliefs of teachers were significantly more favourable to their IBI practices for the most experienced teachers compared to those with 15-25 years' experience as well as less than 5 years' experience. For the science qualifications of teachers, the post hoc comparisons did not reveal any significant differences. However, the simple knowledge beliefs of teachers generally increased as their science qualifications decreased.

Significant interactions were also detected between the two independent variables $(\mathrm{df}=6, \mathrm{~F}=2.334, \mathrm{p}=.032)$. Figure 1 . below shows the profile plot of teachers' simple knowledge beliefs based on their teaching experience and science qualifications. The chart shows that the simple knowledge beliefs of teachers generally increase with teaching experience for teachers with at least one or more CSEC or GCE science subjects. This is not the same for teachers with no CSEC or GCE subjects where no discernible pattern is detected. 


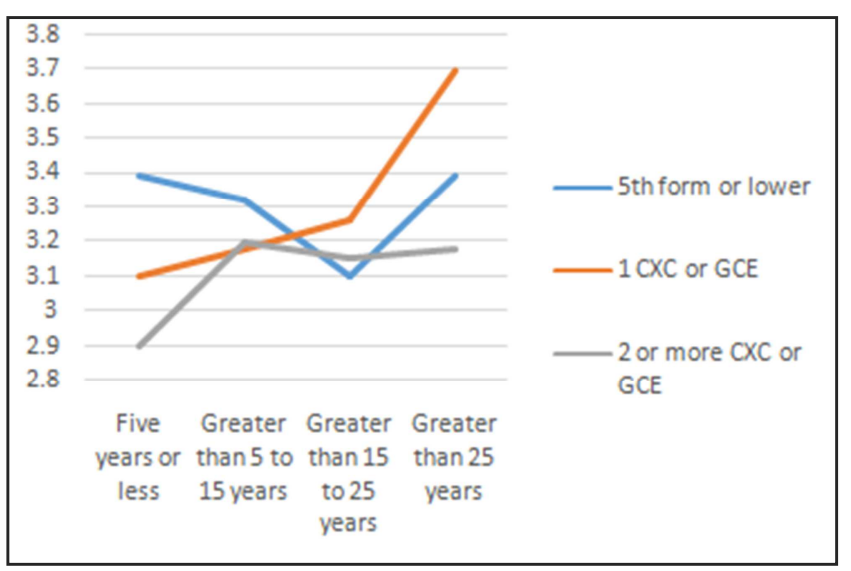

Figure 1. Teachers' simple knowledge beliefs based on teaching experience and science qualifications.

Teaching experience.

The results of the t-test to determine any significant differences in teachers' epistemological beliefs based on teachers' educational attainment showed that the beliefs of teachers with at least a Bachelor's degree are significantly higher than those without a degree $(\mathrm{t}=-1.968$, df $=300$, $\mathrm{p}=.05$ ).

For the t-test to determine any significant differences in each of the underlying constructs of teachers' epistemological beliefs based on teachers' educational attainment, significant differences were only seen in the simple knowledge subconstruct which measures teachers' beliefs about the structure of knowledge. The beliefs of teachers with at least a Bachelor's degree are significantly higher than that of those without a degree $(\mathrm{t}=-2.136, \mathrm{df}=300, \mathrm{p}<.05)$.

\subsection{Analysis for Research Question 3}

How do the levels of primary school teachers' epistemological beliefs predict their levels of IBI practices?

In the first part of the research Samuel and Ogunkola (2013) found that the teachers in the sample practiced a level of IBI at the unsatisfactory developing inquiry level. While the teachers practiced at the proficient inquiry level for instructional factors, it was in the level of discourse, assessment and curriculum factors that they fell short where the level practiced for each was at the developing inquiry level of instruction.

For the regression analysis to determine the extent to which the teachers epistemological beliefs could be said to predict their IBI, the correlation was significant $(\mathrm{p}<.0005)$ with a moderately positive correlation coefficient of 0.422 . The $\mathrm{r}^{2}$ value of 0.16 indicates a medium effect size as advised by Kinnear and Gray (2011).

Pearson's correlation was also conducted to determine the extent to which teachers' epistemological beliefs predict each of the component factors of teachers' IBI. Only teachers' discourse factors was significantly predicted by their epistemological beliefs, with the regression being moderate and positive $\left(\mathrm{r}=.354, \mathrm{r}^{2}=.13, \mathrm{p}=.001\right)$.

\section{Discussion}

Deniz (2011) suggested that teachers with more sophisticated epistemological beliefs are more likely to engage in IBI compared to those with the more naïve beliefs. Teachers' epistemological beliefs were found in this study to be only moderately favourable towards IBI practices. A sizable $83.4 \%$ of the teachers in the sample were found to have only moderately favourable epistemological beliefs while $14.6 \%$ of them actually have unfavourable beliefs. This is an important finding because of the nature of epistemological beliefs and its general importance to how teachers view their role in the teaching learning process. These moderately favourable beliefs may, at least partly, account for the reliance of many teachers on teaching practices that are not inquiry-based. However a better understanding of these findings is realized when one examines the results for the underlying constructs of epistemological beliefs. It is important to look at these underlying constructs separately because, as explained by Kienhues et al (2008), these beliefs can be regarded as independent and so individuals may hold simple beliefs for one construct and sophisticated beliefs for a different construct.

For teaching practices, the definitions of the underlying constructs of epistemological beliefs clearly illustrate that simple epistemological beliefs are more favourable to traditional content-focused teaching practices while the more sophisticated epistemological beliefs favour IBI practices. Therefore, the findings that teachers have epistemological beliefs that are only moderately favourable to IBI should be of concern to education authorities. These findings, however, do indicate that this concern should really be towards four of the underlying constructs: beliefs about the certainty, authority, and simplicity of knowledge as well as innate ability. The fifth underlying construct, beliefs about the speed of learning recorded favourable scores. So the way teachers perceive knowledge and learning may not be having as positive an impact on their science teaching practices as may be required.

The moderately favourable beliefs about innate ability would impact on the way teachers perceive the ability of all their students learning the science content. The simple belief is that learning potential is fixed at birth compared to the sophisticated belief that learning potential is improvable. So some teachers may actually not be giving the required attention to some students who they deem incapable of learning the science content. This violates a basic tenet of IBI that all students can learn. There would therefore be an indirect impact on the student-centeredness of the teaching practices.

The simple beliefs about the certainty of knowledge is that knowledge is stable and unchanging, while the more sophisticated belief is that knowledge is tentative, changeable and constructed by the knower. Teachers' moderately favourable 'certainty of knowledge beliefs' is therefore an indication that many of them may have more of the simple 
beliefs that is unfavourable towards the practice of IBI. Viewing knowledge as stable and unchanging is contrary to the fundamental underpinnings of constructivism which is strongly linked to IBI. The teacher's role in IBI was actually regarded by Ibrahim (2003) as the same as in a constructivist classroom.

Of similar concern are the moderately favourable 'omniscient authority' beliefs of teachers where the simple belief is that knowledge originates from authoritative sources compared to the more sophisticated belief that knowledge is constructed by the knower based on reason, empirical evidence and critical thinking. The many teachers who have the more simple beliefs may, based on these beliefs, be more likely to practice the more traditional modes of science instruction where the science content is simply presented to the students without engaging them in experiences which allow for critical thinking and individual construction of knowledge.

'Simple knowledge' beliefs range from the simple belief that knowledge consists of isolated concepts to the more sophisticated beliefs that knowledge consists of integrated concepts. The problem-based nature of IBI requires that information relevant to a problem be accessed from a variety of sources and even from other subject areas. Students must also be made to see relevance among and relationships between concepts. This requires the more sophisticated 'simple knowledge' beliefs. The simple beliefs of many teachers, as indicated by the moderately favourable 'simple knowledge' beliefs, should therefore be of great concern.

In dealing with these moderate epistemological beliefs, education authorities must take into consideration factors that led to the development of these beliefs. Jones and Carter (2007) indicated that personal epistemologies develop from a combination of formal and informal learning experiences. In formal schooling, students' personal epistemologies may partly develop as a result of the manner in which they were engaged by teachers in the learning of content in the various subject areas. The research literature gives ample evidence that this engagement was mainly teacher centered and content focused. Kienhues (2008) cited studies which suggested a positive relationship between the more sophisticated epistemological beliefs and effective learning strategies as well as better learning outcomes of students. This, of itself, indicates the importance of a formal educational environment which fosters the development of the more sophisticated epistemological beliefs in students, and hence, eventually teachers.

Although there is less evidence of the impact of informal learning experiences, it can reasonably be argued that these experiences may have at least as great an impact on epistemological beliefs as the experiences of schooling. Society provides many avenues for informal as well as formal learning opportunities that may have as great an impact on individuals' thought processes as the classroom environment. One example encountered by the researcher in the lesson observation phase of this study is the religious beliefs of teachers which were actually reflected in a number of science lessons where teachers attributed the authority of God or the bible to events such as the origin of life, the universe, and nature generally; actually contradicting the scientific information that they had, with the encouraging approval of students. It is also noticeable that the research findings indicate that the epistemological belief construct that teachers received the lowest score for was the omniscient authority beliefs.

While education authorities may not be able to do much about the effects of societal avenues of learning on teachers thought processes, they do have a measure of control over what happens in the classroom. The low level of teachers IBI may actually be promoting the development of the more simple epistemological beliefs in students, some of whom will become teachers. The cycle will just keep going on and on unless solutions are found that would best encourage teachers to use the IBI that was learnt and practiced during their years of teacher education. This may involve a rethinking of the teacher education process that would better allow student teachers to face and even challenge their entering beliefs. Chi-Kin Leo et al (2013) actually suggested that teacher educators could more facilitate the professional development of teachers by encouraging them to be conscious of their epistemological beliefs.

Although Jones and Carter (2007) are of the view that teachers' epistemological beliefs tend to be stable and resistant to efforts to change them, Pajares (1992) cites Piaget's accommodation theory as a means of how these beliefs could be altered in the same way that misconceptions are altered. So if the student teachers are provided experiences where they are dissatisfied with their existing beliefs, and the new beliefs are made to seem intelligible and plausible, then the opportunity is there for a meaningful change in epistemological beliefs. The study by Kienhues et al (2008) actually found that the naïve epistemological beliefs of a group of university students changed to more sophisticated beliefs using teaching strategies based on the principles of conceptual change. Deniz (2011) did a similar study but with teachers as the target group, and found similar results.

The findings of this study also revealed that teachers' epistemological beliefs showed an increase with teaching experience. The underlying construct directly responsible for this increase is the 'simple knowledge' beliefs where the beliefs of teachers with more than 25 years' experience were found to be significantly more favourable towards IBI than those with 15-25 years' experience, as well as those with less than 5 years' experience. It was also found that this increase in the favourability of teachers' 'simple knowledge' beliefs with experience was only for teachers with science qualifications of at least $1 \mathrm{CSEC}$ or GCE subject. There was no such increase for the many teachers without CSEC or GCE science subjects. These results are very interesting in that, firstly, they indicate that for some reason, as teachers gain experience teaching, their 'simple knowledge' beliefs increase. A possible reason can be deduced from considering the nature of these beliefs. 'Simple knowledge' beliefs range 
from the belief of knowledge as isolated concepts (simple) to the belief of knowledge as integrated concepts (sophisticated). It can be reasonably argued that as a teacher gains experience teaching, especially in the primary school where one teacher teaches different subjects, he or she may gradually realize the multitude of connections that can be made between concepts from within a subject area, as well as between subject areas. Hence they may become more sophisticated in their beliefs about the structure of knowledge.

The second interesting observation from the results on teachers' simple knowledge beliefs is that the increase in the favourability of teachers' 'simple knowledge' beliefs with teaching experience was only for the teachers who had at least one science subject at the CSEC or GCE level. It was only from the year 2007 that the entry requirements for teacher training in St. Lucia was changed so that the trainees had to have at least one science subject at the CSEC or GCE level. This means that, as revealed by this study, there are many qualified teachers in St. Lucia teaching science who do not have this minimum qualification. The results of this study suggests that, for these teachers, even becoming more experienced does not result in they becoming more sophisticated in their epistemological beliefs as compared to their more qualified counterparts.

Even though the findings only indicate a moderate prediction of IBI practices, it nevertheless indicates the importance of sophisticated epistemological beliefs in science teachers. However, the results for the component factors of IBI revealed that teachers' epistemological beliefs were moderate predictors of only teachers' discourse factors. This is in agreement with the findings of Saker (2010) that teachers' epistemological beliefs determine the nature of their interactions with students. The epistemological belief construct was also the only one which predicted teachers' discourse factors. This is not surprising since discourse factors describe how teachers manage the verbal interactions among teacher and students. This would be significantly determined by teachers' beliefs about the ability of their students to learn the science content, and their beliefs about whether knowledge is certain and from authoritative sources or tentative and constructed by the knower.

\section{Conclusion}

There are probably an abundance of factors that could influence teachers' day to day decisions about their instructional practices. This study focused on teachers' epistemological beliefs as possible predictors of their IBI practices in science. The findings that these beliefs are generally moderately favourable to the practice of IBI should be of concern to education authorities. Since individuals' beliefs arise from their experiences, it is reasonable to expect that these moderately favourable beliefs were formed as a result of teachers' educational experiences.

Teachers' moderately favourable epistemological beliefs suggest certain deficiencies in their formal as well as informal learning experiences. For example, their omniscient authority beliefs, which received the lowest favourability score of the underlying constructs, indicate the possibility that teachers were accustomed to educational experiences where they received and learnt information primarily from authoritative sources like their school teachers, text books and religious ministers. Their moderately favourable simple knowledge and certain knowledge beliefs may also have resulted from educational experiences in which subject content were presented as absolute truth, with minimal effort from teachers to show relevance and relationships between concepts. Finally, their moderately favourable innate ability beliefs probably stemmed from classroom experiences where students were treated differently based on their perceived learning potential.

The level of teachers' epistemological beliefs was also found to significantly predict teachers' IBI practices with teachers with more sophisticated beliefs practicing a higher level of IBI than those with the more naive beliefs. Since these beliefs develop gradually as a result of a variety of formal and informal learning experiences, the key to improving primary school teachers' epistemological beliefs may lie in identifying the type of experiences that lead to unfavourable epistemological beliefs, and applying the necessary interventions.

\section{References}

[1] Abd-el-Khalick, F., Boujaoude, S., Duschl, R., Lederman, N. G., Mamlok-Naaman, R., Hofstein, A., Tuan, H. (2004). Inquiry in science education: International perspectives. In E. Krugly-Smolska \& P. C. Taylor (Eds.). Cultural and Comparative Studies (pp. 397-419). Retrieved May 3, 2011, from

http://www.d.umn.edu/ bmunson/Courses/Educ5560/readings /AbdElKhalick-Inquiry.pdf.

[2] Anderson, R. D. (2002). Reforming science teaching: what research says about inquiry. Journal of Science Teacher Education, 13 (1), 1-12.

[3] Boldrin, A., \& Mason, L. (2009). Distinguishing between knowledge and beliefs: Students' epistemic criteria for differentiating. Instructional Science, 37 (2), 107-127. doi: 10.1007/s11251-007-9038-1.

[4] Bybee, R. W., Powell, J. C., \& Trowbridge, L. W. (2008). Teaching Secondary School Science: Strategies for Developing Scientific Literacy $\left(9^{\text {th }}\right.$ Ed. $)$, Ohio: Pearson: Merril Prentice Hall.

[5] Chan, K. W. \& Elliot, R. J. (2000). Exploratory study of epistemological beliefs of Hong Kong teacher education students: Resolving conceptual and empirical issues. Asia Pacific Journal of Teacher Education, 28 (3), 225-234. Clark, C. M., \& Peterson, P. L. (1986). Teachers' thought processes. In M. C. Wittrock (Ed.). Handbook of research on teaching $\left(3^{\text {rd }}\right.$ Ed.). (pp. 255-296). New York: Macmillan.

[6] Chan, K. W. \& Elliot, R. G. (2004). Relational analysis of personal epistemology and conceptions about teaching and learning. Teaching and Teacher Education, 20, 817-831. http://dx.doi.org/10.1016/j.tate.2004.09.002. 
[7] Chi-Kin Leo, J., Zhang, Z., Song, H., Huang, X. (2013). Effects of epistemological and pedagogical beliefs on instructional practices of teachers: A Chinese perspective. Australian Journal of Teacher Education, 38 (12), 119-146.

[8] Data Management, Corporate Planning Unit, Ministry of Education and Culture. (2011). Education statistical digest, 2011: Past trends, present position and projections up to 2015/16. Curriculum and Materials Development Unit: Castries, St. Lucia.

[9] Deniz, H. (2011). Examination of changes in prospective elementary teachers' epistemological beliefs in science and exploration of factors mediating that change. Journal of Science Education and Technology, 20(6), 750-760.

[10] Hofer, B. K. (2008). Personal epistemology and culture. In M. S. Khine (Ed.), Knowing, knowledge and beliefs: Epistemological studies across diverse cultures (pp. 3-22). The Netherlands: Springer. http://dx.doi.org/10.1007/978-1-40206596-5_1.

[11] Hurling, M. (2014). The effect of teachers' epistemological beliefs on practice. (Doctoral dissertation), Proquest.com.

[12] Ibrahim, A. I. (2003). Design and initial validation of an instrument for measuring teacher beliefs and experiences related to inquiry teaching and learning and scientific inquiry (Doctoral dissertation). Retrieved from http://etd.ohiolink.edu/view.cgi?acc_num=osu1061565152

[13] Inquiry in motion. Transforming k-12 science and mathematics education (2007). Retrieved from http://iimweb.clemson.edu/?page_id=166

[14] Irez, S. (2007). Reflection oriented qualitative approach in beliefs research. Eurasia Journal of Mathematics, Science and Technology Education, 3(1), 17-27.

[15] Jones, G. M., Carter, G. (2007). Science teacher attitudes and beliefs. In Sandra K Abell \& Norman G Lederman (Eds.). Handbook of Research on Science Education. (pp. 10671104). Routledge: New York.

[16] Karabenick, S. A. \& Moosa, S. (2005). Culture and personal epistemology: Middle Eastern students' beliefs about scientific knowledge and knowing. Social Psychology of Education, 8, 375-393.

[17] Kienhues, D., Bromme, R., \& Stahl, E. (2008). Changing epistemological beliefs: the unexpected impact of a short term intervention. The British Journal of Educational Psychology, 78(4), 545-565. doi: 10.1348/000709907X268589.

[18] Kinnear, P. R., \& Gray, C. D. (2005). IBM SPSS 18 statistics made simple. New York: Psychology Press.

[19] Lortie, D. (1975). School teacher: A sociological study. Chicago: University of Chicago Press.

[20] Mann, J. (2014). An investigation on the relationship between epistemological beliefs and instructional practice of preservice and in-service teachers. (Doctoral dissertation), Proquest.com.

[21] Marshall, J. C., Smart, J., Horton, R. M. (2010). The design and validation of EQUIP: An instrument to assess inquirybased instruction. International Journal of Science and Mathematics Education, 8(2), 299-321. doi: 10.1007/s10763009-9174-y.
[22] National Research Council. (NRC) (1996). National science education standards. Washington, DC: National Academic Press.

[23] Nespor, J. (1987). The role of beliefs in the practice of teaching. Journal of Curriculum Studies, 19(4), 317-328. doi: 10.1080/0022027870190403.

[24] Nisbett, P. E., Ross, L. (1980). Human inferences: Strategies and shortcomings of social judgment. Englewood Cliffs, NJ: Prentice Hall.

[25] O. E. C. D. (2009). Creating effective teaching and learning environments: Teaching and Learning International Survey. Paris: OECD Publishing.

[26] Organization of Eastern Caribbean States Reform Unit (OERU) (2007). OECS curriculum harmonization: Science and technology education learning outcomes. Grades k-6. Castries, St. Lucia: OERU.

[27] Ozdemir, I \& Koksal, N. (2014). The evaluation of elementary school teachers' epistemological beliefs. Journal of Faculty of Educational Sciences, 47 (1), 301-326.

[28] Pajares, M. F. (1992). Teachers beliefs and educational research: Clearing up a messy construct. Review of Educational Research, 62 (3), 307-332.

[29] Plourde, L. A. (2002). Elementary science education: The influence of student teaching-where it all begins. Education, 123 (2), 253-259.

[30] Richardson, V. (1996). The role of attitudes and beliefs in learning to teach. In J. Sikula (Ed), Handbook of Research in Teacher Education. (pp. 102-119). New York: McMillan.

[31] Samuel, D. F. \& Ogunkola, B. J. (2013). St Lucian elementary school teachers applicability beliefs and beliefs about science teaching and learning: Relevance to their inquiry-based instructional practices in science. International Education Studies, 6 (7), 48-65.

[32] Saker, H. (2010). Applicability of the approaches-related beliefs of prospective teachers. Problems of Education in the $21^{\text {st }}$ Century, 25, 138-150.

[33] Schommer, M (1990). The effects of beliefs about the nature of knowledge on comprehension. Journal of Educational Psychology, 82 (3), 498-504. doi: 10.1037//00220663.82.3.498.

[34] Schommer, M. (1994, April). Beliefs about knowledge and learning. Paper presented at annual meeting of American Education Research Association, New Orleans, USA.

[35] Schraw, G., Bendixen, L. D., \& Dunkle, M. E. (2002). Development and validation of Epistemological Beliefs Inventory (EBI). In B. K. Hofer \& P. R. Pintrich (Eds), Personal epistemology: The psychology of beliefs about knowledge and knowing. Mahwah, NJ: Erlbaum.

[36] Song, L, Hannafin, M. J., \& Hill, J. R. (2007). Reconciling beliefs and practices in teaching and learning. Educational Technology Research and Development, 55(1), 27-50. doi: 10.1007/s11423-006-9013-6.

[37] Soper, D. (2012). Statistics calculator. A-priori sample size calculator for multiple regression. Retrieved from http://www.danielsoper.com/statcalc3/calc.aspx?id=1 . 
[38] Stoddert, T. (1994, April). The role of teachers' personal learning experience in changing their mathematics instruction. Paper presented at annual meeting of American Education Research Association, New Orleans, USA.
[39] Yilmaz-Tuzan, D., \& Topcu, M. S. (2008). Relationships between preservice teachers' epistemological beliefs, epistemological world views and self efficacy beliefs. International Journal of Science Education, 30(1), 65-85. 